\title{
Pemberdayaan Komunitas Pemulung Melalui Koperasi Pemulung Berdaya di Tangerang Selatan
}

\author{
Maudisha Alifa Rahman ${ }^{1}$, Isbandi Rukminto Adi ${ }^{2}$ \\ ${ }^{12}$ Fakultas Ilmu Sosial dan Ilmu Politik, Universitas Indonesia \\ maudishaar@gmail.com adi1126@yahoo.com
}

\begin{tabular}{l}
\hline Article Info \\
Article history: \\
Article Accepted: 01 July 2021 \\
Publication : 15 July 2021
\end{tabular}

Keywords:

Empowerment, Koperasi.

Pemulung.

\begin{abstract}
This article was developed based on research that examines community empowerment through Koperasi Pemulung Berdaya using qualitative approaches and in-depth interview methods to six informants directly involved in the activities and understand and be able to provide good and correct information related to the focus of research conducted. The findings of this study show that those who are members of Koperasi Pemulung Berdaya feel the well-being both economically and socially. This form of empowerment is done by educating, assisting and raising awareness and providing training so that the scavenger community incorporated in the cooperative has the skills to cultivate their potential and can develop their quality of life.
\end{abstract}

Keywords:

Pemberdayaan, Koperasi,

Pemulung.

\begin{tabular}{l}
\hline Abstrak \\
Artikel ini dikembangkan berdasarkan penelitian yang mengkaji \\
mengenai pemberdayaan masyarakat melalui Koperasi Pemulung Berdaya \\
dengan menggunakan pendekatan kualitatif dan metode wawancara secara \\
mendalam kepada enam informan yang terlibat langsung dalam kegiatan serta \\
memahami dan dapat memberikan informasi secara baik dan benar yang \\
berkaitan dengan fokus penelitian yang dilakukan. Temuan dari penelitian ini \\
menunjukkan bahwa mereka yang tergabung dalam Koperasi Pemulung \\
Berdaya ini merasakan kesejahteraan baik secara ekonomi maupun sosial. \\
Bentuk pemberdayaan yang dilakukan dengan cara mengedukasi, mendampingi \\
dan menumbuhkan kesadaran serta memberikan pelatihan agar komunitas \\
pemulung yang tergabung dalam koperasi mempunyai keterampilan untuk \\
mengolah potensi yang mereka miliki dan dapat mengembangkan kualitas hidup \\
mereka. \\
\hline This is an open access article under the Lisensi Creative Commons Atribusi-BerbagiSerupa 4.0 \\
c) (1) @ \\
\hline
\end{tabular}

Corresponding Author:

Maudisha Alifa Rahman

Fakultas Ilmu Sosial dan Ilmu Politik,

Universitas Indonesia

Email: maudishaar@gmail.com

\section{PENDAHULUAN}

Indonesia merupakan salah satu negara berkembang yang memiliki beragam permasalahan salah satunya adalah kemiskinan. Menurut Badan Pusat Statistik (BPS) mencatat jumlah penduduk miskin September 2020 perkotaan naik sebanyak 876,5 ribu orang (dari 11,16 juta orang pada Maret 2020 menjadi 12,04 juta orang pada September 2020). Sementara itu, pada periode yang sama jumlah penduduk miskin perdesaan naik sebanyak 249,1 ribu orang (dari 15,26 juta orang pada Maret 2020 menjadi 15,51 juta orang pada September 2020. Masalah kemiskinan selalu menjadi perhatian semua pihak untuk dipecahkan, penyebabnya juga bermacam-macam dan begitu juga dengan upaya menanggulanginya. Pada dasarnya kemiskinan selalu mengarah kepada tingkat kesejahteraan masyarakat yang rendah. Kemiskinan bukan hanya kekurangan kebutuhan utama (pokok) seperti sandang dan pangan saja, tetapi juga kebutuhan tambahan lainnya seperti pemukiman yang sehat, air bersih, kesehatan, sumber energi, pendidikan, transportasi, dan rekreasi. Di luar dari kebutuhan-kebutuhan pokok tersebut, ada 
kebutuhan yang paling dianggap penting oleh masyarakat yaitu kebutuhan akan mata pencaharian, karena dengan mempunyai mata pencaharian akan memudahkan akses masyarakat kepada pemenuhan kebutuhan pokoknya.

Permasalahan kemiskinan serta lingkungan hidup yang terkait dengan kesejahteraan masyarakat ini merupakan permasalahan yang harus diatasi secara bersama-sama. Tidak hanya sebagai tanggung jawab pemerintah, tetapi juga tanggung jawab berbagai pihak. Sebagai salah satu perusahaan dan merek kelahiran Indonesia, Danone Aqua berusaha memberikan kebaikan kepada masyarakat dengan menyediakan hidrasi sehat sekaligus memelihara keberlangsungan alam. Selain itu, Danone Aqua juga berusaha untuk menciptakan siklus hidup baru bagi seluruh kemasan plastik yang ada di pasaran, mengoptimalkan pengumpulan sampah secara bertanggung jawab serta menuju kemasan yang $100 \%$ dapat didaur ulang. Pada tahun 2010, Danone Aqua dengan dukungan Danone Ecosystem Fund, mengembangkan model bisnis sosial di beberapa wilayah untuk mengurangi dampak sampah plastik ke lingkungan. Model bisnis sosial yang dipilih untuk unit Tangerang Selatan adalah Unit Daur Ulang Inklusif dengan membentuk koperasi dengan nama Koperasi Pemulung Berdaya untuk mengumpulkan dan memproses botol plastik bekas menjadi cacahan plastik, serta menciptakan dampak sosial dan ekonomi bagi komunitas yang terlibat didalamnya. Berangkat dari realitas sebagaimana disebutkan, penelitian ini difokuskan untuk mengkaji bentuk pemberdayaan pada komunitas pemulung yang dilakukan melalui Koperasi Pemulung Berdaya.

\section{METODE PENELITIAN}

Penelitian ini menggunakan pendekatan kualitatif. Pendekatan kualitatif menghasilkan data deskriptif berupa kata-kata tertulis dan lisan dari orang-orang dan perilaku yang diamati. Seperti yang dikemukakan oleh Creswel (1994: 2), penelitian kualitatif adalah proses pencarian data untuk memahami masalah sosial yang didasari pada penelitian yang menyeluruh (holistic), dibentuk oleh kata-kata, dan diperoleh dari situasi yang alamiah. Melihat dari tujuan penelitian ini, maka jenis penelitiannya adalah penelitian deskriptif. Penelitian ini mempunyai tujuan untuk memberikan gambaran, deskripsi atau lukisan terhadap suatu permasalahan secara sistematis, sifat-sifat serta hubungan antar fenomena yang diselidiki. Seperti yang dikemukakan oleh Neuman bahwa penelitian deskriptif bertujuan untuk memberikan gambaran secara detail tentang situasi, setting sosial, dan hubungan baik dengan menggunakan kata-kata maupun angka serta untuk menyajikan profil, klasifikasi jenis, atau garis besar langkah-langkah untuk menjawab pertanyaan seperti siapa, kapan, di mana, dan bagaimana (Neuman, 2014: 38).

Pendapat tersebut sejalan dengan tujuan penelitian untuk menemukan dan menganalisis secara detail bentuk pemberdayaan pada komunitas pemulung di Koperasi Pemulung Berdaya yang dijelaskan dengan kata-kata bukan dengan angka-angka. Dalam penelitian kualitatif tidak menggunakan istilah populasi tetapi narasumber, partisipan atau informan.

\section{HASIL DAN PEMBAHASAN}

Koperasi merupakan gerakan ekonomi rakyat maupun badan usaha yang berperan dalam mewujudkan kehidupan masyarakat untuk lebih maju. Oleh karena itu Koperasi dapat dianggap sebagai salah satu strategi pemberdayaan untuk membantu masyarakat menyelesaikan permasalahan yang mereka hadapi, baik permasalahan ekonomi, sosial dan lingkungannya. Masyarakat diarahkan agar menjadi masyarakat mandiri, yaitu yang mampu menguasai atau berkuasa atas kehidupannya.

Koperasi Pemulung Berdaya yang menjadi lokasi penelitian berada di kecamatan dengan luas paling kecil yaitu Kecamatan Setu. Kecamatan Setu merupakan pemekaran dari Kecamatan Cisauk, Tangerang dengan batas sungai Cisadane, sebelah barat sungai Cisadane masuk Kec. Cisauk dan sebelah Timur masuk Kec. Setu. Berdasarkan data yang didapat dari Badan Pusat Statistik Kota Tangerang Selatan, penduduk Kota Tangerang Selatan berjumlah 1,35 juta jiwa dengan presentase penduduk bekerja adalah 91,52\%. Persebaran penduduk khususnya 
di Kelurahan Setu hanya sekitar 6\% dari keseluruhan penduduk yang ada di Kota Tangerang Selatan dan merupakan presentase yang paling kecil dibandingkan kelurahan lain.

Koperasi Pemulung Berdaya ini merupakan salah satu program binaan dari perusahaan Danone Aqua. Danone Aqua adalah pionir dalam program daur ulang dan pengumpulan botol plastik bekas melalui program Aqua Peduli (Pengelolaan Daur Ulang Limbah) pada tahun 1993. Melalui Program Aqua Peduli yang diselenggarakan pada tahun 1993, Danone Aqua telah menjadi pionir dalam program daur ulang dan pengumpulan botol plastik bekas. Melalui program ini, Danone menarik kembali botol plastik bekas dari konsumen melalui outlet distributor di Indonesia. Sampah Botol plastik bekas tersebut ini kemudian melalui proses pembersihan dan pencacahan yang kemudian diekspor ke Taiwan pada saat itu.

Semenjak dimulainya program ini, industri daur ulang limbah botol plastik pun berkembang di Indonesia karena botol plastik bekas telah mempunyai nilai ekonomi. Lebih lanjut, Danone Aqua membangun model sosial bisnis unit daur ulang/ Recycling Business Unit (RBU) di Tangerang Selatan, dan bersama dengan mitra industri daur ulang menginisiasi sejumlah RBU, dua di Bali, dua di Bandung, dan satu di Lombok. Keenam RBU tersebut setiap tahun mengumpulkan rata-rata 12.000 ton botol plastik bekas. Danone Aqua membangun siklus hidup baru botol plastik menjadi sumber daya yang bernilai guna. Botol-botol plastik bekas yang terkumpul didaur ulang sehingga dapat menjadi bahan baku botol baru, selain itu botol plastik bekas tersebut juga menjadi komponen penting dalam produksi tekstil, geo textile untuk pembangunan jalan tol, stripping ban, dakron dan produk lainnya yang dibutuhkan untuk industri maupun rumah tangga.

Unit Daur Ulang Inklusif atau Inclusive Recyling Business Unit (RBU) resmi berbadan hukum dengan nama Koperasi Pemulung Berdaya Tangerang Selatan pada tahun 2013. Dalam bisnis unit daur ulang/ Recycling Business unit (RBU) ini, pemulung berperan penting dalam proses pengumpulan botol di RBU maupun dalam ekosistem daur ulang di Indonesia. Namun, kebanyakan dari mereka tidak memiliki status kependudukan di wilayah mereka tinggal dan bekerja, sehingga pemulung sulit mendapatkan akses kesehatan. Menyadari hal tersebut, bersama dengan RBU, Danone membuka fasilitas kesehatan gratis dan akses BPJS. Danone-Aqua juga mendukung RBU di Tangerang Selatan untuk mendapatkan sumber botol plastik bekas dari wilayah DKI Jakarta, seperti dari Hotel Shangrilla dan termasuk di Kepulauan Seribu. Di DKI Jakarta, Danone mendukung Dinas Kebersihan dan Lingkungan Hidup Jakarta Barat menginisiasi Bank Sampah Induk Satu Hati. Jaringan Bank Sampah Induk terdiri dari 45 unit bank sampah masyarakat unit, 5 unit bank sampah sekolah di seluruh Jakarta Barat.

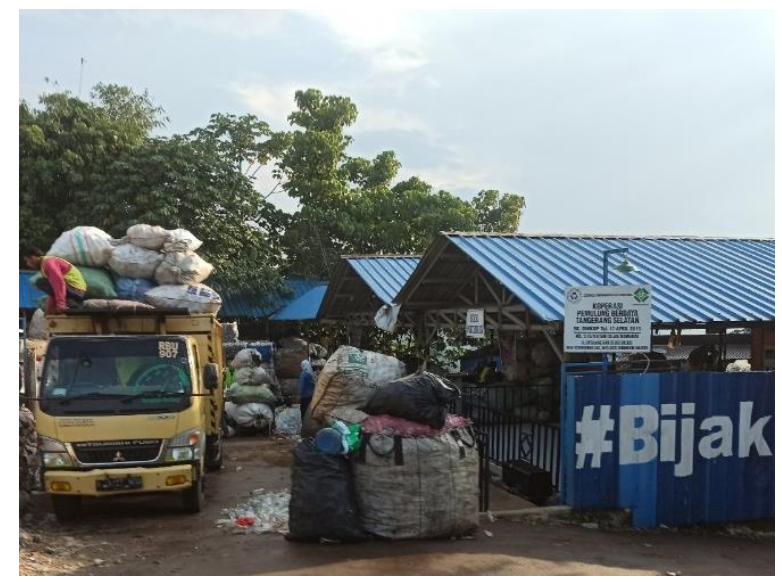

Gambar 1. Tampilan depan Koperasi Pemulung Berdaya

Pada pelaksanaannya, Koperasi Pemulung berdaya ini berdiri diawali dengan mengindentifikasi permasalahan serta berdiskusi dengan salah satu mantan pemulung yang kini menjadi ketua dari Koperasi Pemulung Berdaya. Pada saat itu, antara dari pihak Danone Aqua dan mantan pemulung tersebut saling bertukar ilmu. Pihak Danone Aqua memberikan edukasi 
serta pelatihan untuk bagaimana sampah botol plastik ini bisa didaur ulang yang hasilnya menjadi lebih profit dan produktif. Selain itu, Danone Aqua juga menggandeng beberapa LSM untuk memberikan pengetahuan serta pemahaman kepada komunitas pemulung bagaimana cara berorganisasi. Begitu juga dengan mantan pemulung ini, memberikan pengetahuan kepada pihak Danone Aqua terkait dengan sampah plastik yang dapat didaur ulang.

Untuk saat ini, RBU Tangerang Selatan telah berdiri secara mandiri melalui entitas Koperasi Pemulung Berdaya walaupun tetap terus di damping oleh Danone Aqua. Operasional RBU meliputi pengumpulan dan pengelolaan kemasan plastik paska konsumsi. Dalam mengumpulkan botol plastik, RBU Koperasi Pemulung Berdaya mendapatkannya dari berbagai sumber, mulai dari lapak hingga dari bank-bank sampah masyarakat yang sudah bekerjasama dengan Danone Aqua. Dalam sebulan, RBU Koperasi Pemulung Berdaya ini bisa mengumpulkan sampai 150 ton sampah botol plastik. Dalam pengumpulan sampah botol plastik ini, para pekerja bagian purchasing merupakan yang paling berperan untuk mendapatkannya. Setiap hari, mereka mencari lapak-lapak untuk membeli sampah botol plastik yang berkualitas, bernegosiasi dengan para pelapak dan dapat membeli sampah botol plastik tersebut dengan harga sesuai dengan standar yang sudah ditentukan.

Jangkuan dalam mencari lapak meliputi daerah Jabodetabek hingga ke Pulau Seribu. Para pekerja purchasing ini juga seringkali ditemani oleh para pekerja supir angkut barang, hal ini dilakukan agar dapat langsung membawa sampah-sampah botol plastik yang berhasil untuk dibeli.

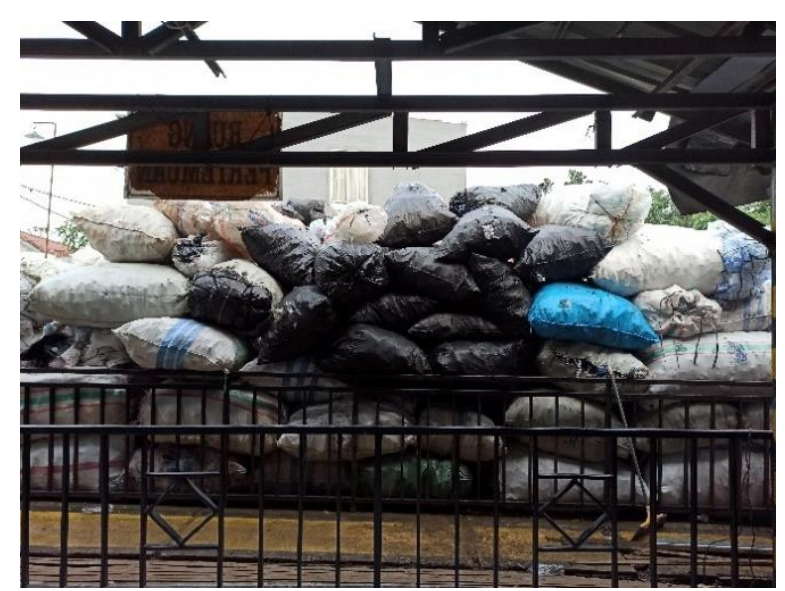

Gambar 2. Sampah botol plastik yang telah dikumpulkan

Selain dari para pelapak untuk mendapatkan sampah botol plastik, RBU Koperasi Pemulung Berdaya juga mendapatkan sampah-sampah botol plastik dari kerjasama yang sudah dilakukan oleh Danone yaitu dengan bank sampah yang ada di Jakarta.

Setelah barang didapatkan dan didatangkan ke RBU Koperasi Pemulung Berdaya, sampah-sampah botol plastik tersebut akan ditimbang terlebih dahulu sebelum nantinya akan masuk pada tahap penyortiran. Pada tahap penyortiran ini, sapah-sampah botol plastik yang sudah ditimbang akan dipindahkan ke tahap berikutnya dengan menggunakan mesin conveyor. Pada sisi samping mesin conveyor ini, sudah ada beberapa pekerja yang siap untuk memilah dan menyortir sampah botol plastik yang tidak dapat diproses agar tidak ikut masuk ke dalam tahap penimbangan. Sampah plastik yang sudah ditimbang akan dipisahkan menurut jenisnya, yakni plastik yang berbahan dasar bening dan plastik yang berbahan dasar biru muda. Selain itu, di tahap ini juga disortir kembali sampah-sampah yang tidak bisa diproses namun lolos ditahap penyortiran yang pertama. 


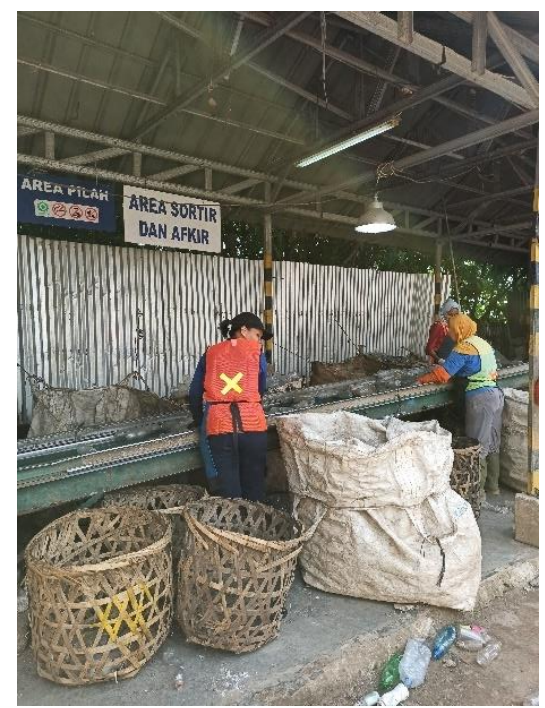

Gambar 3. Kegitan sortir

Setelah sampah botol plastik dipisah menurut jenisnya, maka akan dialirkan menuju penggilingan. Sampah plastik tersebut digiling hingga menjadi cacahan plastik, Kemudian, cacahan plastik ini dialirkan menuju mesin pencucian sekaligus pengeringan sehingga siap untuk dipacking. Namun, pada perjalanan menuju packing, cacahan plastik tersebut kembali disortir oleh beberapa pekerja yang siap untuk memisahkan cacahan plastik yang tidak layak jual dan dapat memengaruhi kualitas cacahan plastik yang dihasilkan.

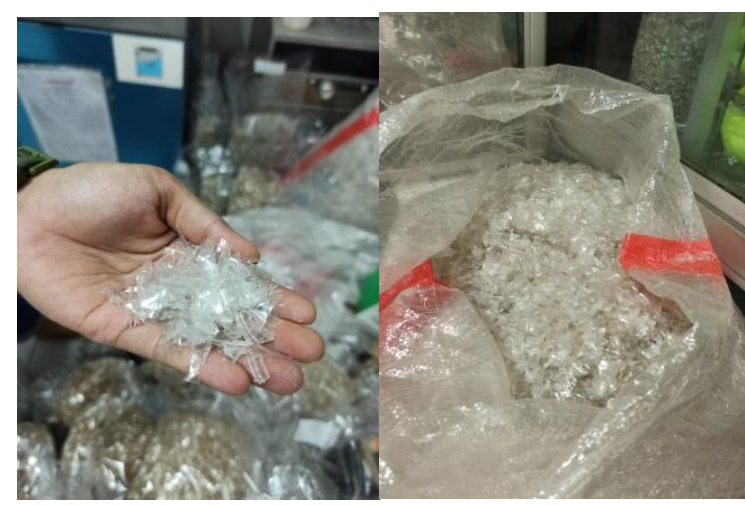

Gambar 4. Cacahan plastik dari hasil penggilingan

Cacahan plastik yang disimpan dan sudah melalui tahap uji lab dengan hasil sesuai dengan standar nilai jual, selanjutnya cacahan plastik tersebut akan diangkut dan dikirimkan menuju mitra industri daur ulang seperti PT Namasindo Plas untuk kemudian di proses kembali menjadi bahan baku botol baru dengan material daur ulang. Selain itu, dikirimkan juga kepada mitra industri PT Kahatex yang merupakan rekanan manufaktur tekstil H\&M, dimana serpihan diolah menjadi bahan poliester daur ulang yang nantinya akan dibuat pakaian anak ramah lingkungan. 


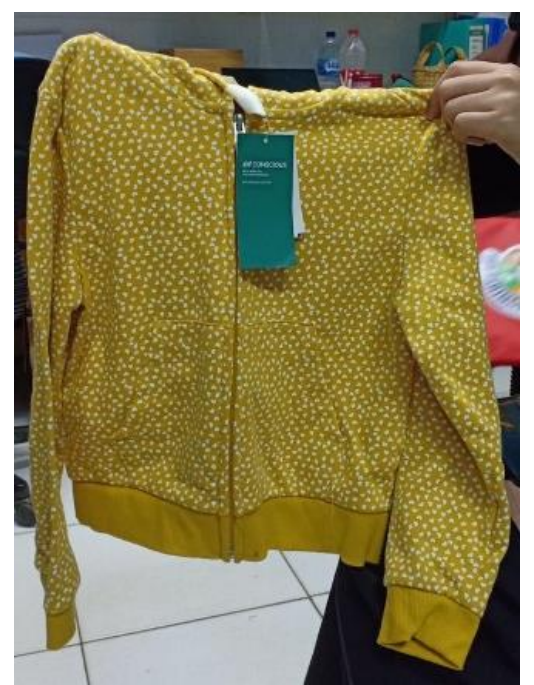

Gambar 5. Salah satu contoh produk H\&M pakaian anak ramah lingkungan

Dari hasil penemuan tersebut, hal ini sejalan dengan yang dijelaskan Hogan (2000:20) dimana ia menggambarkan tentang proses pemberdayaan yang berkesinambungan sebagai suatu siklus. Proses pemberdayaan akan berlangsung selama komunitas itu masih tetap ada dan mau berusaha memberdayakan diri mereka sendiri.

Mengenai manfaat yang didapat oleh para anggota koperasi, fasilitas yang didapatkan oleh para pekerja di Koperasi Pemulung Berdaya ini adalah gaji pokok, uang lembur, bonus jika memenuhi target produksi sebesar minimal 20\% dari gaji. Para pekerja juga mendapatkan jaminan BPJS yang dibayarkan 70\% oleh RBU dan 30\% oleh para pekerja di Koperasi Pemulung Berdaya. Selain itu, di Koperasi Pemulung Berdaya ini juga menyediakan beasiswa bagi pekerja yang putus sekolah. Mereka yang mendapatkan beasiswa akan dibiayai pendidikannya untuk ikut paket A, Paket B atau Paket C. Serta, para pekerja ini mendapatkan akses simpan dan pinjam uang guna memenuhi kebutuhan hari-hari ataupun kebutuhan mendesak.

\section{KESIMPULAN}

Pemberdayaan yang ada dalam RBU Tangerang Selatan atau yang kini sudah berbentuk badan hukum dengan nama Koperasi Pemulung Berdaya merupakan pemberdayaan yang menyinergikan antara pemberdayaan ekonomi dan pemberdayaan lingkungan dengan cara mendaur ulang sampah botol plastik menjadi materi bernilai jual. Gerakan ini, tidak hanya memberikan manfaat baik bagi para anggota Koperasi Pemulung Berdaya tetapi juga dapat mengurangi pencemaran sampah plastik dan menciptakan lingkungan yang lebih baik.

Dari gerakan ini juga, tidak hanya komunitas pemulung yang dapat bergabung tetapi masyarakat sekitar yang mempunyai latar belakang berbeda juga dapat bergabung dan mendapatkan manfaatnya dari pemberdayaan yang dilakukan.

Anggota yang tergabung dalam Koperasi Pemulung Berdaya merasa lebih berdaya daripada sebelumnya ketika mereka belum bergabung dengan Koperasi Pemulung Berdaya. Dalam kegiatan daur ulang ini, mereka diberikan pengetahuan dan beberapa pelatihan mengenai daur ulang sampah botol plastik, sehingga saat ini mereka mampu menghasilkan sampah botol plastik yang berkualitas dan bernilai jual. Selain itu, kegiatan ini juga memberikan manfaat lain yang dirasakan oleh para anggota yaitu rasa kekeluargaan dalam lingkungan kerja. Dimana mereka mengaku bahwa dalam kegiatan ini, mereka sangat diperhatikan dan diberi kemudahan dalam setiap masalah yang dialami. Serta, dengan adanya kegiatan ini memberikan juga kesadaran bagi mereka untuk lebih berbuat baik pada lingkungan dan rasa untuk saling membantu satu sama lain, terutama terhadap sesama anggota.

\section{SARAN}

Dalam rangka pemberdayaan komunitas pemulung melalui koperasi pemulung berdaya di Tangerang Selatan, maka ada beberapa rekomendasi sebagai berikut: 
1. Dari hasil temuan lapangan yang ditemukan bahwa dalam pelaksanaannya mereka memiliki beberapa kompetitor yang mempunyai bisnis usaha serupa di sekitarnya, sehingga Koperasi Pemulung Berdaya ini harus lebih memperluas jaringan baik dalam mendapatkan bahan baku berkualitas ataupun kerjasama dengan mitra industri, agar unit usaha ini dapat terus hidup dan berkembang.

2. Diharapkan gerakan ini juga didukung dan berkolaborasi dengan pemerintah setempat sehingga tidak hanya mengembangkan bisnis daur ulang sampah plastik tetapi juga ikut menumbuhkan kesadaran masyarakat sekitar agar dapat mengelola sampah serta bijak dalam menggunakan sampah plastik serta dapat menjadi salah satu agen penyumbang sampah botol plastik untuk bisa didaur ulang dan mendatangkan profit.

\section{DAFTAR PUSTAKA}

Adi, Isbandi Rukminto. Intervensi Komunitas dan Pengembang Masyarakat (Sebagai Upaya Pemberdayaan Masyarakat). PT. Raja Grafindo Persada : Jakarta. 2012.

Creswell, John, 1994, Research Design: Qualitative and Quantitative Approaches, London: SAGE Publications

Harahap, Friska Indria Nora. 2017. Jurnal. Pemberdayaan masyarakat pemulung sampah Sungai Citarum melalui Koperasi Bangkit Bersama. PLS UPI.

Hasbullah, J. 2006. Social Capital (Menuju Keunggulan Budaya Manusia Indonesia). Jakarta: MR-United Press.

Hogan, Christine. 2000. Facilitating Empowerment: a Handbook for Facilitators, Trainers and Individuals. London. Kogan Page Limited.

http://ecosysteme.danone.com/projectslists/pemulung/ diakses 20 Juni 2021

https://www.bps.go.id/pressrelease/2021/02/15/1851/persentase-penduduk-miskin-september2020-naik-menjadi-10-19-persen.html diakses 20 Juni 2021

Ife, Jim dan Tesoriero. 2008. Community Development: Alternatif Pengembangan Masyarakat di Era Globalisasi Edisi Bahasa

Midgley, James. 2005. Pembangunan Sosial Perspektif Pembangunan dalam Kesejahteraan Sosial. Jakarta: Diperta Depag RI

Neuman, W. Lawrence. (2014). Social Research Methods: Qualitative and Quantitative Approaches Seventh Edition. Edinburgh Gate, Harlow: Pearson Education Limited

Research Design: Qualitative and Quantitative Approaches (California: SAGE Publications, Inc, 1994) 